\title{
Hundred per cent successful throughput rates of Master's and doctoral research students
}

\author{
K Rochford* \\ University of Cape Town
}

\begin{abstract}
This article describes how 25 Master's and doctoral students commenced their dissertations, with the writer as their supervisor, and how all subsequently succeeded in graduating, many within a time period of one to three years. These students also efficiently produced 18 articles in refereed journals, ten refereed published interna tional conference papers, ten papers published in national conference proceedings, ten published seminar papers and several books as an integral part of the work for their dissertations. Most of these publications were written, under guidance, by students who either originated in historically disadvantaged backgrounds, or were handi capped by speaking English as a second lan guage, or both. The article presents and discusses the teaching strategies, interventions and time management techniques adopted to ensure research student success even under adverse conditions, resulting in zero dropouts and a zero throughput failure rate under super vision from the early 1980s through to 2002 .
\end{abstract}

\section{INTRODUCTION}

$\mathrm{H}$ annah" (not her real name) walked into my office 18 months ago. "I want you to be the supervisor of my Master's dissertation," she said.

Her written work had been serially abandoned as incurably "unfocussed" by three consecutive lecturers under whom she had attempted to initiate a research investigation.

I gazed at her and responded: "I am not a research supervisor; I am a research coach. Do you need a research supervisor or a research coach?"

Her eyes went deeply downcast as she whispered recognition of her own problem, "I need a coach. With your detailed help I was able to publish an investigative coursework paper two years ago, and present it publicly at a national conference. Since that time I have got nowhere with other lecturers as supervisors of my intended dissertation topic."

Hannah's case is by no means atypical. Throughout the world it is anticipated that three quarters of Master's students who commence a dissertation under research supervisors will never graduate. One university department in South Africa recently orally reported a Master's throughput success rate of only $5 \%$. Another recent report records that $85 \%$ of students in higher education never graduate (Asmal 2002). Records of the last seven years in a certain university department with which I have had close contact, show that two Master's/doctoral students out of every three either failed or dropped out permanently.

However, work is different in my office. We are able to record a virtually $100 \%$ successful throughput rate with Master's and doctoral students because I choose to be a daily research coach, not a fortnightly research supervisor/advisor/mentor. This response change began nearly 20 years ago when my university adopted a different policy of admitting applicants to a Master's degree programme. Suddenly prospective students were invited to tick on their Faculty application form that they were "in need of regular, detailed supervision; a taught programme and dis sertation".

In reality, for many students the word "regular" meant "daily" for three years, not fortnightly because the student whose written work was persistently error

\footnotetext{
* Contact person:

K Rochford

University of Cape Town

Fax 0216503489

Phone 0216502777

e mail KR@humanities uct ac za
} 
prone would be wasting 13 days out of every 14 by going seriously off track, unchecked, just one day after every meeting with the supervisor. It was more efficient for the supervisor to correct half a page of new work submitted each day, rather than to try to untangle a build up of many pages of incorrect work after two weeks.

The word "detailed" meant that the supervisor would have to re write almost every sentence of the student's written attempts several times. Every second or third written word would be submitted by the student unchecked, or as a guess or as an inaccurate approximation.

The word "taught" meant that several times each week the supervisor would have to explain repeatedly and teach in detail why every paragraph written by the student was inappropriately phrased, was unclear had inconsistent typographical errors, was wrongly referenced, and so on.

In short, the onus was placed on the lecturers to respond to students who, right from the outset, were honest enough to request close personal assistance for the duration of their Master's degree programme. Some lecturers, needing more time to obtain their own personal $\mathrm{A}, \mathrm{B}$ or $\mathrm{C}$ research ratings to be awarded by the NRF, continuously refused to super vise any of these students. There was no praiseworthy recognition for doing so.

Two years ago I was invited to take part in a university research methods course run by a small team of lecturers. I began by saying to the class of 45 students:

"Most of you have been registered now for a Master's degree for $2 \frac{1}{4}$ years. How many of you have never held a dissertation on a table in front of you, or taken one off a library shelf?"

About 25 students raised their hands. Unbelievably, more than half the class naively expecting to graduate at the end of the year, in this their third year had never even opened or looked inside a disserta tion. Instead, they had spent two years of a Master's degree programme simply writing one terminal cour sework essay after another. As anticipated, these students realised too late that they had already lost two years of valuable dissertation writing time, while some of their co fellows who made research their individual priority two years ago instead had already published their dissertation research and graduated. Thus, many of those who had still not started a dissertation in their third year of registration realised and declared that they "now had a mountain to climb"; and they simply dropped out of the Master's programme permanently and were promptly forgot ten.

One student at another university, who did submit a half dissertation for examination, found the deadline for completion had been too close. The dissertation was returned to him. It contained more than 550 listed errors.

Another Master's student, "James", recently tele phoned me. I asked about the progress he had been making on his minor dissertation. He said he hoped to be submitting it for examination at the end of that year. In January 1995 I had previously volunteered to commence supervising his Master's dissertation to gether with the dissertations of two other incoming Master's students at the same time. However, he declined. He said he wanted to take the coursework route option first, then his dissertation with other lecturers later. Seven years later, moving from one university to another, and being offered more and more "bridging" coursework modules, he still had neither submitted his dissertation nor graduated.

Meanwhile, one of his historically disadvantaged fellow students, who also commenced in January 1995, had followed my advice to commence his Master's dissertation immediately and to spend the year publishing his emerging dissertation research findings in cited, refereed international journals. Working from Mondays to Fridays on his dissertation, and only at the weekend on coursework papers, this student completed his whole degree in eleven months in the same year, and graduated with distinction. He then went on to complete his doctorate in 2000 and became a lecturer, senior lecturer and then associate professor. By contrast, his fellow student and co equal, who had insisted on pursuing the Master's coursework options first, still had not graduated in 2001, after commencing early in 1995.

\section{ORIGIN OF THE PROBLEM}

The problem of non completion of Master's degrees has been complicated by the long standing debate over what constitutes an "approved" Master's degree.

During the 1970s, South African teachers' diplomas and degrees were classified in steps for category and salary recognition purposes (Education Gazette 1979). Qualified teachers with "matriculation + four years" of diplomas from teachers' colleges could advance to a maximum of Category D. Category F, however, could be reached only if the teacher gained a recognised degree. Category $G$ could be attained only by the teacher achieving a recognised Master's degree. In other words, to attain Category G, in addition to holding a university degree, a teacher would have to acquire three more qualifications: a postgraduate diploma in education + a postgradu ate coursework BEd degree (including research methodology courses) + a Master's degree by full dissertation only.

So stringent were the requirements for attaining 
category G that, during the 1970s, Faculties of Education were honoured if they produced even two MEd dissertation graduates per decade.

In the final analysis, promotion within the Cape Education Department depended crucially on the ability of a schoolteacher to create, write and complete a full Master's dissertation independently and accurately with minimal research supervision, and assessed by three independent examiners.

Teachers who openly admitted that they lacked the ability to produce an original 200 page research dissertation on their own, now found an impenetrable professional qualifications barrier to their future promotion prospects.

Perceiving this ceiling to be unacceptable, small groups of teachers approached university staff in some Faculties of Education in the late 1970s, seeking a change in the nature of the MEd degree. They requested an alternative Master's degree pre dominantly by taught coursework and completed essay papers, similar in structure to the BEd degree in which they had succeeded well, but terminal in that it would neither equip nor qualify the holder to proceed to doctoral studies later. Some teachers had already acquired such coursework Master's degrees by visiting overseas universities on study leave. These returning South African teachers were disappointed that their newly obtained qualifications were not being officially recognised as "approved" or "on a par" with the Category G dissertation Master's degrees being issued by South African universities at the time.

Thus, the proposal for introducing an equivalent South African Master's degree by coursework, as a relatively easy sequel to the existing postgraduate BEd degree by course work and research report, was debated at length. It was controversial, and has remained so for nearly 25 years, as the research dissertation component of the South African Master's degree became progressively reduced from $100 \%$ to $60 \%$ to $50 \%$ to $37 \frac{1}{2} \%$ to $0 \%$. This resulted in various forms of the new Master's qualification being "ap proved" or "not approved", as education students tried to avoid committing themselves to a substantial research dissertation for as long as possible.

This unfolding background resulted in students being enrolled initially for large class "coursework" Master's degrees in which commencement of the individual's research dissertation was repeatedly delayed. While this approach might be suitable for some Master's degree students, others eventually fell away during the dissertation phase for which they said they had been inadequately prepared, according to their writ ten comments and feedback to lecturers on their programme evaluation sheets.

It is against this background that the coping strategies described in this article for research shy, supervisor dependent Master's dissertation students were devel oped, and have succeeded. The 25 students men tioned in this article most of whom were hesitant and in need of weekly structure also efficiently produced 18 articles in refereed journals, ten refereed published international conference papers, ten papers published in national conference proceedings, ten published seminar papers and several books, as an integral part of the work for their successful disserta tions.

\section{BACKGROUND}

Lessing and Schulze (2002:139) report that, in higher education, attrition rates and completion rates of postgraduate students are statistics that are becoming of vital concern. At the University of the Western Cape, for example, only $10 \%$ of Master's students completed the dissertation in three years (Sayed. Kruss \& Badat 1998:175)

Ngcongo (2000:211) describes her experiences of supervision at the Master's level at the University of Zululand. She records that a number of students embark on their Master's degrees without sufficient background in and experience of research. She argues that these can be overcome through building capacity and facilitating the self esteem of students.

In a subsequent article (Ngcongo 2001:53) she points out that the supervision and promotion of Master's and doctoral students is an important activity through which university staff perform their teaching and research roles. She goes on to introduce a number of models of supervision and promotion of students. Among these are the Harvester Model (Rademeyer 1994:94), the Bridging Course Model (Phillips \& Pugh 1996:187) and the Cohort Model.

Thompson and Sedlacek (1988) surveyed 41 former research assistants. They generally agreed that their experiences as research assistants had enhanced their competencies as researchers; and felt most competent when collaborating with colleagues on research and in scholarly presentations at meetings.

Shook (1988) reported that classes on the writing of research papers could be made more realistic by: (1) requiring students to find some problem in their professional, personal or academic life needing to be solved by research; (2) ensuring that students were already familiar with the topic on which they were going to carry out their research; and (3) requiring students to choose topics that were practical rather than theoretical, and technical rather than academic. Students were encouraged to use well designed articles as models for the format of their research papers.

Hockey (1996:360) says that the research mentor/ 
advisor should be able to supervise not only the intelligent, independent, enthusiastic and creative students with perseverance and initiative, but also the "difficult" ones who do not show these char acteristics.

This article therefore explains, presents and discusses the teaching strategies, interventions and time man agement techniques adopted to ensure success by many "difficult" students, even under adverse condi tions, resulting in zero dropouts and a zero through put failure rate under supervision.

\section{THE INTERVENTION APPROACH TO POSTGRADUATE TRAINING}

During the last twenty years, the University of Cape Town (UCT) has been attracting increasing numbers of under prepared students into its Master's degree programmes. Students choosing the option of a Master's degree by course work and minor disserta tion usually state that they have had no previous research experience, and they come from all popula tion and language groups. Typically unfocussed, hesitant and with untapped learning potential, they sometimes tend to prefer an "on looker" role in research for as long as possible, instead of the role of confident, independent, accurate and reliable investigator with strong initiative.

As a result, many tend to require and favour an efficient, regular or daily, editing, monitoring, tracking and written system of instantaneous feedback. They tend to delay or avoid data collection, or to approach it initially with considerable uncertainty. They need to benefit from prompt, local, practical discoveries rather than pursuing extensive reviews and studies of numerous theories. They are supervisor dependent not supervisor independent.

They tend, initially, to ignore simple data gathering instruments that, although unspectacular, are readily available; instead they tend to have a diffuse preliminary research focus. This emanates from un realistic ambitions to devise complex instruments with which to investigate exciting but educationally "elastic" variables rather than confining their intended research to more mundane, stable, robust, less adventurous variables. They also often fail, at first, to anticipate difficulties inherent in trying to obtain repeated and complete data from intact groups of respondents over periods of time and in trying to process and analyse incomplete sets of data.

In order to help these students to cope with the pressures to be placed on them, the last thing that many dissertation students with potential should be experiencing is yet another year long programme in which they sit inconspicuously among classroom masses attentively listening to lectures.
What they require is usually individual, personal, face to face coaching, attention, feedback, unleashing of potential, strengthening and sometimes remediation (not mass training) to overcome earlier weaknesses and develop specialised coping strategies. Because they may continue to express themselves in writing in a wayward manner, many compromise their goals and require a long term on going maintenance pro gramme. They tend to need effective case manage ment and constant rehabilitative practice on account of their inability to detect when they have relapsed into subliminally entrenched errors, perhaps as a result of earlier incorrect teaching at school.

They generally lack training in how to distil out interesting aspects of a research narrative from a massive amount of information. Sometimes they may be afraid to ask questions because they have difficulty identifying which questions to ask.

Supervisor dependent research students, from all cultures and backgrounds, tend greatly to under estimate the amount of time and expense required to organise, conduct and evaluate their research, and to disseminate their findings. They need to avoid competing and conflicting interests for their time and attention. Finally, they require an encouraging, reinforcing, comprehensive, individual and group emotional support system.

This article describes how these characteristics of under prepared research students have been tackled successfully during the last two decades, and it outlines the strategies and techniques adopted to meet the students' needs.

\section{FOURTEEN CHARACTERISTICS OF SUCCESSFUL UNDER-PREPARED RESEARCH STUDENTS IN EDUCATION}

At the University of Cape Town, the following features have usually characterised our successful research graduates in education originating from academically under prepared communities during the last fifteen years:

- They successfully save months or years of time and expense when, under specific guidance, they arrive on academic Registration Day with sets of tables of simple, systematic data that they have already recently obtained.

One way of making this possible at UCT is by conducting intensive short full time vacation courses in research data gathering exercises one or two months prior to the university's annual Registration Week, with undivided attention being given to the prospective re search students' skills and needs.

- Within eight weeks of commencing work under their research supervisor/coach, they will have 
attained their first major goal which is the complete write up of the first draft of Chapter 4 of their dissertation: the chapter of basic Results.

By commencing their programme of studies with their own real data generated from their own pilot studies followed by an improved major exercise in data gathering in their own unique classroom, school or educational situa tion, students are keen to learn and apply a variety of data purification and data analysis techniques. They are highly motivated to dis cover things immediately about their own meaningful working lives.

- They rapidly develop confidence and skills when instructed to confine their initial data gathering to the use of educational instruments which occupy no more than one page. Typically these will comprise no more than about a dozen simple, pertinent items in a conveniently available scale or interview schedule or battery of evaluation criteria, etc.

At UCT we have a number of such recently developed data generating instruments on hand. Under prepared prospective research students who are supervisor dependent are usually quick to seize the opportunity to translate them into another of South Africa's eleven official languages. Then they can quickly obtain new data in more pilot studies, to improve the interview schedule or refine the new scale, to derive its new statistical para meters with larger groups of respondents, and so on.

- Under prepared supervisor dependent students quickly develop confidence and research skills by being restricted to the investigation of less exciting but more stable and robust and clear cut variables in their data collection (such as gender; age group; home language; etc)

At UCT we initially discourage prospective research students from their suggestions that they investigate more ambitious, contested and enthralling variables (such as "teaching ability", "social justice", "empowerment", "sustainabil ity", "maladministration", "social equality", "creative leadership", etc.) These may be too diffuse, elastic, panoramic, messianic or ambig uous for emerging, inexperienced researchers to define operationally and defend.

- They produce research reports more efficiently by being required to meet numerous, small, 24 hour deadlines for written submissions of half a page, one page or two pages, every day or so, right throughout the year.

At UCT this is achieved by research super visors/coaches making themselves available for instantaneous correction of research students' written work at, say, 16 h00 every day from Monday to Friday on an automatic basis. Only after the student is responding to this estab lished working habit consistently for months does the lecturer finally agree to be officially appointed as the candidate's supervisor.

Anticipating up to 20 to 30 errors in every new page of work submitted each day, the research supervisor/coach reminds the English second language student that, even after all the chapters have been completed, the entire dissertation will still have to be re checked 12 to 14 times. This may require an independent team of proof readers, language experts and technical editors. When attempting to make corrections, the under prepared student will simply type in more but different errors; or wrongly delete words, sentences or paragraphs; or confuse the new page numbering; or copy revised references incorrectly; and so on.

- They are more productive, and demonstrate far more overt confidence, when they are required to focus, first of all, on the rapid dissemination of their initial practical discoveries and findings.

The second major goal for each student is the submission of a manuscript for refereed pub lication within four months of commencing work under a research supervisor/coach. Hav ing improved their drafts of Chapter 4, and having drafted Chapter 3 in response to daily face to face corrections, half a page per day, the manuscript can now be commenced. It may take the form of a short article on emerging research findings, or a conference paper to be presented and published two months hence even if published only as an abstract of preliminary results discovered. Once the stu dents have experienced the joy of initial acceptance and success, only later are wider theoretical contexts introduced to draw the students' attention to possibly fundamental limitations of their apparently accomplished research investigations.

Thereafter, the student will be expected to submit more manuscripts (either long or short) for publication every three or four months. These will subsequently unfold into pre struc tured chapters, systematically developing the sub headings agreed upon in the manuscripts.

- The third major goal is to have four of the students' dissertation chapters completed in draft form within eight months of commencement of the research.

Almost every one of my research students has experienced an upheaval in their lives that is unrelated to the dissertation. Often it occurs about six to eight months after the research has 
begun. A close relative dies; there is a major car accident, a move of house or the birth of a child: and so on. The student announces the need to go away for a month. Provided that four of the six chapters have been written up (even approximately) by the time this major event occurs and if the student's early work is now in press, or has already appeared as a published conference paper then the chances of the weaker student returning to complete the remaining two dissertation chapters are high. If, however, not one of the student's chapters has been satisfactorily completed by this point in time, then the chances of the plodding student being motivated to return after a month's absence are considerably reduced.

- They blossom and flourish under a well designed, caring and comprehensive individual and group emotional support programme.

At UCT this is achieved using a wide range of personalised reinforcement techniques. For ex ample, wherever possible, the support and encouragement of spouses and families are also established before a decision is taken to begin the research.

Another strategy is the on going use of en couraging quotations made by famous educa tors, scientists, philosophers or historians. These might be attached to the cubicle of an individual research student as a form of inspira tion, or included in a note of congratulations on the successful completion of another chapter or article.

- They produce their best work when required to systematise, analyse and present summaries of their qualitative or quantitative findings when they are at their personal financial peak, and when their "reservoir" of emotional and psychological energy is still full.

At UCT we have found that this peak tends to occur about two or three months after registra tion day in the first year of the students' Master's or Bachelor's research degree. This is why we encourage each research student to have his or her first short international article or conference paper ready to submit by this time.

- Supervisor dependent, under prepared research students tend to become highly motivated and productive when gathering common or related data in teams, recording and analysing it together for co authored submission to journals.

Sometimes at UCT we encourage students to collect data for each other, and to share it, but separately to investigate different variables within the data generated by the enlarged combined samples.
- Our under prepared research students benefit by short term and long term pacing schedules.

At UCT we equate the time needed to complete the research dissertation with the pacing re quired by the tapestry weaver or ultra distance swimmer, and the need to maintain freshness and alertness in the closing stages of the endurance event. We advise a five and a half hours per day research work schedule for five days per week throughout the year; and we compare the task which still lies ahead to be similar to the patience and schedule required to complete the making of a long, intricate wed ding dress faultlessly, but on time.

- Emerging novice research students benefit from research supervision which is characterised by single mindedness based on a high profile, visible track record of successes by previous research students from educationally impoverished local or sub Saharan communities.

At UCT prospective research students are introduced to, and left to talk in confidence with, current Master's and Bachelor's research degree students from a wide range of countries. Prospective supervisors' expectations and suc cesses are soon made clear to the incoming novices by the non threatening, encouraging, reassuring and highly motivated group of current research students.

- Novice research students appreciate having access to numerous exemplary theses of recent Master's and doctoral graduates in education laid out permanently on office shelves and/or available to them on diskette.

These remain instantaneously and continuously accessible, usually for seven days a week throughout the year.

- An office wall is covered from ceiling to floor with the students' own off prints, and bearing journals containing their most recent articles, with their published books and names on public display.

These open displays of local students' publica tions and articles in press convey an atmos phere of research dynamism and progress from week to week. They show current students how it is possible to follow in the footsteps of the struggling but successful research students of previous years, who now remain keen to return for higher degrees.

\section{STUDENT FEEDBACK}

Evidence supporting the narratives described above may be obtained by quoting verbatim from the written feedback to lecturers formally supplied by students who have received intensive daily face to face 
coaching assistance with their written research attempts for many months.

A class of 21 students evaluated a new Research Methods course at the end of May 2002. The course comprised $12 \times 2$ hour sessions in the School of Education.

The following are examples of the students' end of course responses:

On selected Likert scale items ( $0=$ not at all; 5 = very much):

"My research proposal is releasing and developing my creative potential." Mean score $4.42=89.0 \%$.

"I feel confident about my research proposal." Mean score $4.05=82.0 \%$.

"I feel that my chances of succeeding in research are ...." Mean score $4.47=90.0 \%$.

"I feel that I am benefiting from my attempts to conduct a research proposal." Mean score $4.33=92.4 \%$.

"Doing a research proposal makes me happy." Mean score $4.17=82.2 \%$.

Sample comments:

- "The course was really an eye opener to me. I have gained a lot. I used to think one had to be a genius to write a research proposal. I have realised that research is not an easy thing to do, yet if one is guided appropriately, one can do very compre hensive research."

- "I realise I have the potential as a researcher and, with encouragement, I can make it."

- "I have learned a lot about research by trial and error. I have often felt I don't really know in which direction to go, or what I am doing. Nevertheless, I really enjoyed doing the pilot studies."

- "I am confident that, with the professional assis tance I have received from my supervisors, I will be able to achieve my goal."

- "Most challenging was the formulation of my questionnaire. Formulating precise questions is not an easy task, and it is very fulfilling when one does it correctly."

- "The research proposal format was most helpful by referring to those proposals done by other re searchers."

- "I have learned to develop competence in the use of methods and techniques that are applied in educational research. Although I struggled in this area, I think in the end I can say I have benefited."

- "Deadlines kept me focused, i.e. having to hand in specific parts of the proposal each week."

\section{DISCUSSION}

A reviewer of this article has pointed out that research capacity building is one of the "key" policy criteria used for determining National Research Foundation (NRF) ratings.

In practice, however, is this necessarily so? The reality is that the NRF will be unlikely to deny individual researchers a valid $\mathrm{A}, \mathrm{B}$ or $\mathrm{C}$ rating if they themselves are performing well, but their personal record of building the research capacity of other people happens to be relatively small. Research capacity building in teams is system dependent, not merely supervisor dependent.

Another reason why "development of the research capacity of other people" cannot always be consid ered as an across the board "key" evaluation criter ion is that one of the stated priorities of deans in South Africa is to obtain valid NRF ratings for as many of their academic staff as possible. Indeed, the public credibility of their faculties depends on this. To achieve as high a percentage of staff as possible with valid initial NRF ratings, effective deans will tend to shield their staff from becoming involved in the supervision of too many inexperienced, time con suming, risky research students.

My experience of supervising 26 theses is that a competent, independent, accurately working Master's degree student will be able to gain distinction for a dissertation with fewer than 50 hours of focused, personal supervision and advice. On the other hand, a student with promising potential, such as one with an inadequate command of the English language, can require 250 to 300 hours of intensive supervision. The importance of this 1:6 learning time ratio for high aptitude/emerging aptitude students has been well documented for more than 30 years (eg Bloom 1971:55); and deans who ignore it do so at their students' peril.

For example, I know of a senior lecturer and a professor who have point blankly refused to supervise the dissertations of all weak students already regis tered for Master's degrees in their areas of specialisa tion. In addition to their above average lecture loads, these academics have been frank in their remarks that supervisor dependent students deprive them of the time they rightfully require to obtain, or to maintain, a valid NRF rating. The students are then simply left to drop out.

As conveyed to me, there is a further problem surrounding the suggestion that research capacity building is a "key" indicator in the NRF rating system of individuals.

I understand that acclaimed, internationally estab lished researchers who devote too much of their time to capacity building will be given lower than expected 
B or even $\mathrm{C}$ ratings by NRF assessment panels. When this happens, such academics will be required to go through an appeal process (if they happen to be aware of its existence) in order to be recognised and awarded the valid rating that these professors deserved in the first place. The time consuming process of reassessment can be complicated still further as a consequence of the NRF's contested policy of using low $\mathrm{C}$ rated or relatively inexperienced academics on their panels to evaluate the research of established $\mathrm{A}$ and $\mathrm{B}$ rated colleagues.

There is yet another difficulty with the NRF's current policy of utilising an individual applicant's record of building research capacity as a "key" criterion for a valid NRF rating. At present there is an NRF requirement to report only positive attempts at building research capacity, including successes when these occur. There is no obligation on an applicant for an NRF rating to report capacity building attempts that were abandoned or failed irrespective of numbers of research students in a particular depart ment who simply faded away and disappeared through lack of dedicated support.

So, how might these dilemmas be managed more effectively, in order to avoid a history of silent cover up?

Firstly, I suggest that the NRF might encourage universities to offer entire honours degrees (particu larly in the humanities) that specialise in the intensive teaching of context based and skills based research methods courses and products only, utilising stu dents' own contributed data. These degrees would be examined through the quality of the products of the students' own research designs, data gathering, data purification and analyses, and their published re search conclusions and reports. Special emphasis would be placed on teaching students how to practise the complex techniques of analysing in depth their own freshly gathered data from as many different perspectives as possible. The acquisition of this preliminary skills and performance based honours qualification by students might help to streamline the subsequent throughput and completion rate of doctoral and Master's dissertation graduates.

Secondly, there exists no completely separate recog nition category of NRF $A, B$ and $C$ ratings for established academics with exceptional records of efficient, effective, responsible and productive stu dent research training and capacity building, per se, including proven high rates of successful through put and high rates of student publications in cited journals.

What is being suggested in this article is that a new and separate rating system of research teaching might be introduced one that accredits efficient and effective quality of student delivery, as distinct from one that merely notes that research students are being supplied with "opportunities" to build. The intention is to eliminate ineffective, low quality implementation. with its associated high dropout rates, as the end result that has occurred repeatedly, and has been played down, in the past.

The introduction and official recognition by the NRF of a parallel rating system of effective research teaching and mentoring might be an important step forward.

Over a period of, say, 20 years, " $A$ " ratings for research teaching might be awarded to research mentors who achieve better than a $90 \%$ successful through put rate of Master's dissertation and doctoral students, from initial registration through to gradua tion, all with refereed publications. "B" ratings might be awarded for an $80 \%$ success rate; and " $\mathrm{C}$ " ratings for a $70 \%$ success rate.

Without the introduction of such a new and different rating system, the NRF cannot complain if Master's and doctoral student dropout and failure rates continue to remain reported regularly at about $75 \%$ $95 \%$.

\section{CONCLUSION}

Our emphasis remains on maintaining optimism, encouragement, using every spare moment to assist research students, caring and standards. We remain confident that, with continued support from an evolving, improving and transforming NRF, students can be encouraged to perform and achieve even better outputs and performances in the future.

\section{ACKNOWLEDGEMENTS}

The financial assistance of the University Research Committee of the University of Cape Town towards the production of this article is acknowledged with sincere thanks. The encouragement and suggestions of the reviewers of the manuscript are also much appreciated

\section{NOTE}

At the time of writing, the author has one student who discontinued work on his dissertation for two years, after a promising start with four conference publications, in order to earn money overseas to pay for his Master's degree studies. He has now returned to Cape Town, and says he will resume next year, 2004. However, should he fail to do so, he will become the author's first ever dissertation dropout. 


\section{REFERENCES}

Asmal, K 2002. Cape Times 5 November.

Bloom, B S 1971. Mastery learning, in Block, J H (ed) Mastery learning: theory and practice. New York: Holt, Rinehart and Winston.

Education Gazette 1979. Cape Education Department, 13 September 469ff.

Lessing, A C \& Schulze S 2002. Postgraduate supervision and academic support: students' perceptions. South African Journal of Higher Education 16(2):139 149.

Ngcongo, R P 2000. Self esteem enhancement and capacity building in the process of supervising master's students. South African Journal of Higher Education 14(1):211 217.

Ngcongo, R P 2001. Supervision as transformative leadership in the context of university goals. South African Journal of Higher Education 15(3):53 57

Phillips, E M \& Pugh, D S 1996. How to get a PhD. Philadelphia: Open University Press.

Rademeyer, G 1994. Thesis supervision: getting the genie out of the lamp. South African Journal of Higher Education 8(2):92 95.

Rochford, K 1996. Successful supervision of historically disadvantaged students' research dissertations. International Journal of Ingenium ISSN 1363 514x, Szpytko, J (ed). University of Mining and Metallurgy, Cracow, 1996(2):66 69.

Sayad, Y, Kruss, G \& Badat, S 1998. Students' experience of postgraduate supervision at the University of the Western Cape. Journal for Further and Higher Education 22(3):275 285.

Shook, R 1988. When worlds collide. Paper presented at the Annual Meeting of the Conference on College Composition and Communication, St. Louis, MO.

Thompson, C E \& Sedlacek, W E 1988. An evaluation of research training. The Testing, Research and Data Processing Unit of the University Counselling Centre. Counselling Centre, Maryland University. 